\title{
Applying Online Media for High School Students
}

\author{
K. Khotimah \& S. Sulistiowati \\ Universitas Negeri Surabaya, Surabaya, Indonesia \\ khusnulkhotimah@unesa.ac.id
}

\begin{abstract}
This study aims to develop an online learning media on nutrition and reproduction material, and to determine the effectiveness of the media. The method was based on Research and Development model by Plomp (1997) through five stages: investigation, design, realization, evaluation and implementation. The data was retrieved through the interviews, questionnaire and test. The online media has been developed, and was considered effective when tested in the experiment. Its use has contributed in increasing the level of students' knowledge in the subject. This result was based on the significant difference between pre- and post-test scores. The implication of this study is that the use of online media can be adopted in the study of nutrition and reproduction for high school students in a wider scope, especially around Surabaya, East Java, Indonesia.
\end{abstract}

Keywords: Online Media; High School Students

\section{INTRODUCTION}

The original designs for most online media are intended for life or commercial purposes. Relationship maintenance, information seeking, amusement, style, and sociability are five common gratifications from social networking services (SNS) and instant messengers (IM) used to meet users' social and psychological needs [6]. In Indonesia, the largest user of this media is teenagers.

Teenagers, or teens, are young people whose ages range between 13 and 19. Teens commonly try to show a different social status in the process of searching for their identity and presence in the community. They usually also want to try and replicate new things, and are easily affected by their surrounding environment. Nutritional or health status is a factor that determines the quality of teenagers' physical being. Optimal nutritional status is determined by the knowledge of nutrition, economic and cultural factors. Thus, nutrition education should be included in the school curriculum [7].

Indonesian national education philosophically views humans as individuals with rights and obligations living in a global society with all its challenges. Hence, education has a goal to develop the potential of students in order to be fully human, humane, and intelligent intellectually, socially, emotionally and spiritually.

According to a survey conducted by the Health Promotion Administration, Ministry of Health and Welfare of Taiwan (2013), however, $10 \%-13.5 \%$ of adolescents aged 15-17 years have had premarital sex, and $8.3 \%$ of them had premarital sex for the first time at age 15 or younger. In addition, $15 \%$ of high school students have had premarital sex, and this percentage has increased over time [5].
Some similar facts were also found in Indonesia. The data revealed by the Director of Youth and Protection of Reproductive Rights, National Family Planning Coordinating Board (BKKBN) Masri Muadz, that there were $40 \%-45 \%$ of adolescents between 14-24-year-old stated that they had premarital sex. The impact of this phenomenon is that there are an estimated 2.3 million cases of abortion every year, of which $20 \%$ were done by teenagers. This case shows the need for the provision of reproductive education for the theme, so this study focuses on senior high school students.

A research conducted by the government (BKKBN) on reproductive health education in a high school located in Majalengka, West Java, Indonesia shows that: (1) educators are teachers of counseling, biology, religion, physical and health education, and citizenship; (2) teaching facilities are very limited; (3) teaching materials are available but not well structured and systematic; (4) methods of teaching are only lectures, question and answer, discussion, roleplays and assignments. The limitation of teaching methods and media causes learning process tend to be monotonous and uninteresting.

Students with different learning styles approach learning differently [3]. With the rise of online technologies, researching the effect of the use of online media for learning has become more important. Previous research on the use of online media in school states that technology is likely to be a common environmental cue that may be especially relevant for students who are enrolled in an online course and hence are interacting with technologies while trying to stay on task [4].

The online media has a weakness in the limited affordability for young people in school as well as the sustainability of the media. Several weaknesses related to online learning according to other studies are a delay in responses, lack of a sense of community and/or feelings of isolation, and perceived level of expertise [11]. However, reality has prompted researchers to develop online media that is able to overcome these deficiencies using online media.

This study intends to focus on students' cognitive learning outcomes of the implementation of the internet-based reproduction health learning. Development of online media as a medium of education was because it is closer to the real situation, more participatory, accessible, affordable, and spacious. According to Sukarno (2010), online system provides learners with easier and wider sources of learning, the materials are not only from the teachers but can also be accessed via the internet [10]. In terms of place and time, online learning process is more efficient and effective because students can 
access their learning subject from anywhere and at any time. Another plus is that online learning can be reached by the entire community either those who pursue formal education or those who do not have opportunity to study at schools. Specifically, this study is primarily intended for: (1) developing the online learning media of nutrition and reproduction; (2) determining the effectiveness of the media in improving students understanding of the subject.

\section{METHOD}

This study used research and development method with a model of educational development proposed by Plomp (1997) through five stages, namely: (1) investigation; (2) design; (3) realization; (4) evaluation and (5) implementation of the device [9]. Respondents were middle adolescents aged 16-18year-old, or at the level of high school students. The research was carried in two places, namely Vocational High School 1 and Vocational High School 6 in Surabaya, East Java, Indonesia. Data of this study was gained from interviews, questionnaire, and test. Primary data consists of (1) the knowledge of students about nutrition and reproduction; (2) the effectiveness of the media; (3) student cognitive and affective abilities as the result of the development of the media. Meanwhile, secondary data includes student data, identification of nutritional and reproductive website that has been developed, students' initial nutritional knowledge, students' perception of reproductive health and nutrition topics, and the result of interviewing an adolescent reproductive specialist.

The level of respondents' knowledge of nutrition and reproduction that indicates the effectiveness of the model was assessed based on respondents' answers to several questions about nutritional needs of adolescents, eating habits, and behavior. It is then categorized into good nutrition knowledge if the answers are $>80 \%$ correct, fair if the answers are 60 $80 \%$ correct, and less if the correct answers are less than $60 \%$.

Practicality is a model used to determine the use of the model by the respondents who assessed the Guttman scale. Affective abilities of respondents rated with Likert scale and given a score of 2 for a correct answer, a score of 1 for hesitation, and a score of 0 for a wrong answer, then categorized into good, fairly good, and less good. Data on respondents' prior knowledge and development models that have been processed were then presented as percentages and analyzed descriptively. Meanwhile, data on the teenagers' cognitive and affective abilities were analyzed using t-test.

\section{RESULT AND DISCUSSIONS}

\section{A. Investigation}

The student's early knowledge of nutrition and reproduction was obtained from disseminating test questions. The tests were conducted on 31 students in Surabaya, East Java in 2015. The number of questions used to assess the initial knowledge of adolescents is 23 questions, with details of 13 questions about nutrition and 10 questions about reproduction. Questions about nutrition knowledge consist of 1) five questions of food and health, 2) five questions of lifestyle that includes drugs, and 3) three questions of cigarettes. The reproductive knowledge includes two aspects which are 1) reproductive organs as many as five questions, and 2) illness due to sexual intercourse as many as five questions.

Each question was scored with a score of 1 for the correct answer and score of 0 for the wrong answer. Furthermore, the overall answers were categorized to be "high" if they were $>80 \%$ correct, "moderate" if they were $60-80 \%$ true and "low" if they were $<60 \%$ true.

The result of nutritional knowledge score shows that food and health problem can only be answered correctly by 3 $(9,68 \%)$ respondents, drug problem cannot be answered correctly by all respondents, and knowledge of cigarette is answered correctly by only one respondent. The result of assessment of respondents' reproductive knowledge is slightly better than their nutritional knowledge, but no respondent can answer all questions about reproductive organs and sexually transmitted diseases correctly. This result proves that the knowledge of nutrition and reproduction of adolescents is still in the "low" category, so it is appropriate to develop media to improve their ability and understanding of nutrition and reproduction.

\section{B. Design}

Device design is done by making the structure or web design. The website is made simple without registration so users can directly open the existing materials. The website structure has eight pages, namely home, news, gallery, repository, quiz, polling, member, and consultation forum. The next process is to upload the material in the pages available on the website. The material is arranged in the form of articles with popular language styles in order to be interesting and easy to understand. The material also features illustrations to clarify the contents of the material.

\section{The Realization}

The website address is www.gizidanreproduksi.net. The website structure consists of several pages including (a) "home" which contains a picture of web identity as well as web creation purposes; (b) "news" containing various articles of nutrition and reproduction; (c) "gallery" containing photos of activities related to the preparation and web-testing activities, (d) "repository" contains some other information to enrich the material in the article, (e) "quiz" in the form of various questions related to the material with an answer key that automatically appears after the user answers the question, (f) "poll" contains a poll to extract the necessary information, (g) "member" containing procedures for registering and logging in to open the web, (h) "consultation forum" is a user-initiated interview page that can be used by users to consult with the experts.

\section{Evaluation}

The evaluation stage is done by two reviewers who are media experts and material experts. The instruments used are questionnaires to assess the feasibility of content, language, and presentation. 
The result of evaluation shows that the average score given by the first reviewer is 4.49 and the second reviewer's validation score is 4.56 . Converted to the predefined criterion value that the average obtained scores range between 3.45 and 4.65 , then it belongs to the "valid" category. The material expert suggests the researchers to complete the contents with the latest data or facts, while the media expert suggests the photo illustrations should be replaced with animated images. Based on the results of the assessment, the device is declared "feasible" to be tested by making improvements as in the advice and input from the experts.

\section{E. Implementation of The Device}

Tests were given to 68 students in two schools. There were 30 items of cognitive test questions on the topic of instant foods, drugs, and sexual aberrations. Questions that measure affective ability consist of 20 items on the topic of instant foods, drugs, abortions and sexual aberrations.

The result of cognitive ability pretest assessment is classified as "moderate" category with score 71,24 , while the score of students affective ability is 76,52 and classified to "high" category. Further posttest results showed an increase in cognitive ability to 84.24. Students' cognitive ability is considered "good" because the score is more than 80 . This cognitive ability is also accompanied by the increase in affective ability with an average score of 85.39. Results of student post-test on cognitive and affective abilities of nutrition and reproduction are better than pretest results. Analysis with different t-test is done to know the real difference of the two values.

\section{CONCLUSION}

Based on the results of the study, it can be concluded that: (1) Students knowledge of nutrition and reproduction are still in the low category $(61.5 \%$ and $70.3 \%)$, especially on the topic of drugs, food, health, reproductive organs and sexual diseases; (2) the development of online learning media about nutrition and reproduction rated valid by experts with the average value of 4.58 ; (3) the test results showed the average score of posttest on cognitive and affective abilities are better than the mean of pretest and there are significant differences from both.

This means that the developed online media quite effectively improve the ability of the students, cultivate the character of independence and curiosity for obtaining information, foster interest in reading habit and responsibility in performing tasks in life.

The online media that has been developed was considered practical and effective for studying nutrition and reproduction. The result of the experiment shows that the online media have succeeded in increasing the level of students' knowledge in the subject. This result was based on the significant difference between pre- and post-test scores. After using online media, we found that the post-test score was higher than the pre-test score. The implication of this study was the online learning media can be adopted in the study of nutrition and reproduction for high school students in a wider scope, especially around Surabaya city or even more East Java.

Suggestions from this research are the need to make continuous improvement of the online media on nutrition and reproduction learning as well as the need to expand the scope of the target users. By doing so, it is expected that the information provided is kept up to date and relevant to students' development.

\section{REFERENCES}

[1] N. Evans, et al, "Adolescent Peer's Perception of Their Health Norms," American Journal of Public Health, It 1064-1069, 1995.

[2] E. Hurlock, Development of Children vol. 1, Jakarta: Airlangga. 1991.

[3] V. Balakrishnan, and C. L. Gan, Students' learning styles and their effects on the use of social media technology for learning, Telematics and Informatics, 33(3), 808-821. https://doi.org/10.1016/j.tele.2015.12.004, 2016.

[4] R. B. Hollis, and C. A. Was, Mind wandering, control failures, and social media distractions in online learning. Learning and Instruction, 42, 104-112. https://doi.org/10.1016/j.learninstruc.2016.01.007, 2016.

[5] J.-C Hong, C.-R Tsai, C. Fan-Chiang, and M.-Y. Hwang, Mindfulness in learning safe sex via social media: Perspectives of personality and experiential value. Com-puters in Human Behavior, 64, 337-346. https://doi.org/10.1016/j.chb.2016.06.033, 2016.

[6] Y.-C. Ku, T.-H Chu, and C.-H. Tseng, Gratifications for using CMC technologies: A comparison among SNS, IM, and e-mail, Computers in Human Behavior, 29, 226-234, 2012.

[7] L. A. Moreno, M. Gonzalez-Gross, M. Kersting, D. Molnar, S. De Henauw, L. Beghin, and B. Ortega, As-sessing, understanding and modifying nutritional status, eating habits and physical activity in European adoles-cents: the HELENA (Healthy Lifestyle in Europe by Nutri-tion in Adolescence) Study. Public health nutrition, 11(3), 288299, 2008.

[8] National Family Planning Coordinating Board (BKKBN), Contraceptives Service in the Indonesian Family Planning Program: History, Approach, Achievement. Jakarta: BKKBN, 1997.

[9] Plomp, Educational and Training System Design. (The Nederlands: The University of Twente, Faculty of Educational Science and Technology), 4-6, 1997.

[10] V.D. Sukarno, Future-Oriented Education Model. http://gemapendidikan.com / 2010/05 / model-oriented education of the future-2 /, 2010.

[11] L. Song, E. S. Singleton, J. R. Hill, and M. H. Koh, Im-proving online learning: Student perceptions of useful and challenging characteristics. The internet and higher education, 7(1), 59-70, 2004.

[12] Out Look. Adolescent Reproductive Health: Making a Difference, Program For Appropriate Technology In Health, vol. 16, no. 3, ISSN:0737-3732, December, 1998. 